\title{
Rediscovering Ourselves as Educators: An Exploration of Our Own Teaching Practices during a Global Pandemic
}

\author{
Tia Frahm \\ Northern Arizona University, USA \\ Amy Spiker ${ }^{1}$ \\ University of Wyoming, USA
}

\begin{abstract}
The purpose of this manuscript is to tell the story of two literacy methods professors' teaching experiences in Fall of 2020. We found ourselves in a unique situation in that one of us was teaching fully online and the other using a hybrid model of both in person and online instruction. Together, we knew that there was something to discover in regard to higher education, specifically preservice service teacher methods courses, that needed to be explored. Therefore, we asked ourselves five reflective questions at the end of each month in the fall semester. Collectively, we decided on these questions as they related most to what we had experienced in Spring of 2020 and what we wanted to further learn from in the Fall. We answered these questions individually and then came together in a zoom meeting to discuss our reflection and anything else that we wanted/needed to share. While we found this process of reflecting and sharing to be cathartic to our own experiences, it was also uncomfortable to bump against our own beliefs about teaching and education in general. As a result, we share our collective conversation based on our reflections. This framework allowed us to move from "teacher lounge" talk and into action because our conversations were more structured and purposeful. We were able to understand ourselves as educators better and provide a framework for reflection for the field of education
\end{abstract}

KEYWORDS: Duoethnography, Education, Methods Courses, Qualitative Research.

The global pandemic of Spring 2020 changed the landscape of teaching and learning in what was once considered to be a priority in-person experience to include asynchronous and synchronous teaching in an online environment. With the shift to an online learning environment, instructional design, strategies, and methods had to shift as well. There was, and rightfully so, a focus on both student and educator's well-being during Spring 2020. However, as the world transitioned to summer, uncertainty toward the fall semester loomed ahead. As literacy methods instructors in two different colleges of education, we began to discuss the challenges of the upcoming Fall 2020 semester and how we were approaching our instruction. This study emerged from that conversation.

This work has value because, in the midst of Covid-19 and adapting to the realities of our ever-shifting teaching contexts, we felt that our voices as instructors were being drowned out by top-down mandates, policy changes, and the voices of concern from students and stakeholders. We also felt frustrated by instructors that seemed to transition to online learning

${ }^{1}$ Corresponding Author E-mail: aspiker@uwyo.edu 
easily while we found ourselves struggling to make sense of teaching literacy methods in an online space. While our work in this duoethnography is an attempt for us to make sense of our experiences teaching in Fall 2020 we seek to support other instructors with a framework of reflection questions to deepen their understanding of their own teaching practices. This framework includes five predetermined questions that guide educators in reflecting on their teaching practices.

We structured this article to flow like a long conversation over a cup of coffee. We begin with a brief rationale for why we choose duoethnography and how we explored our experiences teaching in a global pandemic. Throughout the four months of the study, we answered and reflected on the five questions and then met to discuss our reflections and allowed the conversation to flow for the scheduled hour. By giving ourselves the time and space to reflect, to meet and discuss our evolving teaching practices, and to share how we were making adjustments and moving forward, we were able to make sense of teaching in Fall 2020.

\section{Methodology}

For this study, we engaged in a duoethnographic approach to describe our experiences teaching in Fall 2020. Duoethnography was considered by Norris and Sawyer (2012) as collaborative field testing. This study was similar to a collaborative autoethnography (Creswell, 2013) where we integrated both of our shared experiences. Breault (2016) further explained that duoethnography "brings together elements of autoethnography, autobiography, self study, life history, interviews, and more" (p. 2). Throughout this process we engaged in our own autoethnographies, wrote our teaching autobiographies, engaged in conversations with each other throughout the fall semester, and continually relied on a five-question framework as we reflected on our teaching practices and experiences of engaging in a duoethnography.

For the purpose of this study, we relied on Breault's (2016) paper on duoethnography and, in fact, found ourselves referring to it most often throughout this project. We did not want to solely rely on "parallel talk" (Breault, 2016, p. 6) in that we wanted to make clear how this experience has changed our perceptions of our own teaching and helped to redefine how we position ourselves within the academic community. In fact, at the start of this study, we both wrote and reflected on our own operational definitions of ourselves as teachers, definitions that evolved throughout the study. Therefore, we also took "theory confirmation" (Breault, 2016, p. 6) into consideration as well, and began our study from there. Our purpose in coming together was to capture our experiences in a focused way through the semester - therefore we asked the same questions to keep our reflection focused on areas that we felt were important based on our own experiences as educators. However, as we continued to write through our experiences in the fall semester, analyzed the data, and wrote about how we were moving forward, we discovered a new foundational understanding of ourselves and the field of preservice teacher educators.

\section{Participants}

Though this study was a duoethnography we felt that there were four participants. Two professors engaged in the study; we each wrote our own participant statement to provide a brief understanding of how we situated ourselves within the study. We cannot ignore, however, the pandemic and how it necessitated a move to an online environment. We wrestled with the concept of trust serving as either a participant, or as the foundation for the study. We include it in this section as it served an important role in the study. 
I am a Senior Lecturer in a College of Education at a large state university in the western region of the U.S. I teach literacy and general teacher education courses. My main responsibility is to teach a literacy methods course for preservice teachers the semester prior to their student teaching residency. This course is designed to help them take the theory they have learned in prior courses and apply it to classroom instruction and assessment.

My philosophy of teaching has always been based in teaching as a face-to-face act. I believe that successful teaching begins with a relationship and that is easier to establish in a shared physical space. I also believe that teaching is active and learning to teach must be active and interactive. The methods semester should be filled with activities that allow preservice teachers to try out instructional strategies and assessment strategies. It should be filled with rich dialogue and shared experiences. Teaching is not a solitary endeavor. Teachers work together with colleagues to plan instruction to meet student needs. They discuss assessment results with colleagues. They work with support staff. Their entire day involves working within, and as a member of, a school context. I firmly believe my methods course should prepare preservice teachers for this community of practice.

At the time of writing this my university is solely online for instruction due to the COVID pandemic and health and safety concerns. I am teaching two sections of literacy methods with enrollments of 17 and 23 in a hybrid manner with online instruction and asynchronous video meetings. I have organized my course into weekly modules and each module begins with a one-hour video meeting. This meeting is designed to introduce the content of the module and to allow live discussions with and between students. I have been deliberate in planning this one-hour introduction to both provide explicit instruction and direction as to the week's content and to connect with students in real time once each week.

\section{Tia}

I am in my third year as a tenure track assistant professor whose primary role is teaching ( $60 \%$ or $3 / 3$ course load) literacy focused courses at the undergraduate and graduate level at a teaching institution in the southwest region of the United States. The writing methods course is positioned in the third semester of the undergraduate education program, in students' senior year and the semester before student teaching. This course is the third and final literacy methods course, the first two courses are focused on early literacy and intermediate reading instruction that are taken in the first semester of the program during students' junior year. The primary focus of this course is on writing pedagogy and instruction along with writing practice. This course has a signature assignment that is used for CAEP accreditation purposes. The focus of the assignment is three-consecutive lesson plans that includes planning, teaching, and reflecting and mirrors their student teaching capstone project.

I am a social constructivist and tend to run my courses, both in person and online, interactively with a focus on students establishing themselves as teaching professionals and therefore cater assignments to mirror the work of a classroom teacher. Students often collaborate with each other on the interpretation of state standards; examining vertical articulation of writing standards and what writing instruction looks like in each grade level; engaging in micro teaching through mini lessons, group work, and conferencing; and the development of writing assignments, with scoring guides, that reflect the standards but also the interest of their future students.

Throughout the pandemic, my institution relied on a HyFlex learning model of instruction. In this course specifically, that meant students participated either online or in person synchronously on Monday or Wednesday, as well as asynchronously throughout the week. Currently, I am in week 5 of the semester. Student feedback has been positive on how the course 
is structured. However, I do think that is because I am keeping it simple and only using Google Drive for all materials, I am also recording intro videos for each week, there is purposeful time set aside in class for thinking/reflecting and asking questions. This semester I am more deliberate about my instructional moves than ever before.

\section{Pandemic/Online Environment}

The impetus for this study was the move by both of our universities to online learning due to the Covid-19 pandemic. Studying our teaching during this transition was simply a natural response. Supporting each other during this time was a necessity. The transition was sudden and face to face classes had to be moved online seemingly overnight. Moving a physical class to an online environment was challenging and it is not an equal exchange. The pandemic caused us to think about engaging and connecting with students in different ways. We agreed that simply moving the same content to a new online platform was not an option. We felt we had to adjust our teaching to better meet student needs. In all of our data the pandemic was a participant, a constant presence that influenced and, at times, defined our teaching.

\section{Trust}

We feel that trust served two functions in this study. The first was as a foundation for our relationship with each other. But trust was a participant within the study itself in multiple ways: trust with ourselves as educators, trust in technology, trust with our students, and trust with process of reflection.

"It might go without saying that the intimate, relational requirements of duoethnography make trust between the co-researchers prerequisite. Without such trust, the disclosure and rigorous interrogation of personal stories would be unlikely" (Breault, 2016, p. 4). As Breault reminds us, trust between researchers is a prerequisite for conducting a duoethnography. We had a previous relationship working together in a variety of settings. We taught together in a university classroom, and we planned and delivered professional development for K-12 teachers. We also shared a history of elementary teaching experiences. During this study we had to build upon our level of trust in challenging ways. We had to be honest and authentic. We had to share concerns in a vulnerable manner. We had to ask each other difficult questions and push up against deeply held beliefs. Had we not built upon a foundation of trust we would not have been able to be as authentic with our reflections during this study. Trust was a participant because trust was always there, always needed, always growing throughout the semester.

\section{Data Collection}

The data collected for this research included a questionnaire, monthly reflective meetings, and our own notes during the meetings. We utilized password protected Google Forms and Docs to capture the questionnaire responses and our own notes. Zoom was used to record and transcribe our monthly reflective meetings. However, once we were able to read through the data, the questionnaire became the focus for our analysis and subsequent chronological conversation as it kept us focused on our experience in real time. Those were captured using Google Forms, which also kept us bound to the question that was right in front of us, keeping not only the data but also ourselves focused on our experiences. An email was automatically generated on the last Wednesday of each month that included the Google Form link to be completed.

The questionnaire evolved from our second conversation about this project. We wanted to have a systematic way to capture our experience throughout the semester and came to an agreement on the five questions. We felt that these questions would get to the heart of our 
teaching experiences. After we co-wrote the initial questions, we decided to wait a few days to return to and finalize the questions. Our final questions are included in Table 1. We arrived at these questions because we wanted to keep the questions to a maximum of five so we would be able to complete them in a reasonable amount of time. Also, the five questions related to the questions and concerns that we were wrestling with from the previous spring semester. These items were what we wanted to consider as we taught our way through the fall semester. We knew that we had to include questions related to our own teaching practices and identity, however, we could not discount our students' behaviors and how we adapted the course based on the context of the world around us. Building an inclusive community is always a priority, but Summer of 2020 brought racial injustices to the forefront of education coupled with hyflex learning, we had to reflect on our classroom community.

\section{Table 1}

\section{Reflection Questions}

1: How are our practices changing/adapting this semester?

2: Is our perception of teaching or identity as a teacher changing? In what ways?

3: How are we working to build an inclusive community?

4: What are we adapting or compromising in the course? How are we arriving at these decisions?

5: What are we noticing about student behaviors and learning?

\section{Data Analysis}

In order to uncover what we had in the data, we engaged with it multiple times over a period of time. Therefore, we describe this process in multiple phases, as each phase revealed new themes in our analysis. We describe this process as open qualitative analysis that evolved throughout the phases.

\section{Phase 1}

The initial phase of the analysis process focused on becoming familiar with the data and our experiences. Initially, we printed out the Google Sheet document that included our answers to the questionnaire separated by month and researcher. During the first read through of the data, we deliberately withheld from annotating in any way in order to absorb the data for what it was without adding preconceived thoughts or questions on it.

\section{Phase 2}

In the second phase of the analysis, we gave ourselves permission to annotate on the data in any way that helped us to fully grasp the data. For instance, in this phase, we noticed that we, as instructors, were being more lenient with assignment deadlines and taking away course readings. We also noticed that our communication with students revolved more around mental issues and not so much on course content. These noticings emerged as themes throughout the data. However, in a research meeting, we decided that we wanted to take a different approach to the write up of our data. Instead of a more traditional approach to writing up the analysis and findings, we decided to be a bit more creative. Therefore, we wanted to have the paper read more like a conversation and not present the findings in themes. Knowing that would stay true to our own experiences teaching during a semester like no other. 


\section{Phase 3}

It was during this phase of the analysis that we decided to take a conversational approach to the data. We juxtaposed the data side-by-side in a Google Document. This allowed us to see our responses to each question in chronological order. By looking at the data in this way, it started to read more like a conversation, which is what we wanted. It was here that we started to notice new themes around the data. Specifically, around how we both had different waves of feeling confident or not in our teaching online at different times throughout the semester.

\section{Phase 4}

In our final phase of the analysis, we started to piece together the chronological conversation of the collected questionnaire data. The conversation included text lifted from each of us and organized together by month. Knowing that the conversation itself was not enough to have readers fully understand our experience, we decided to include narration as guideposts. What is presented next is our chronological conversation about our experiences during the fall semester.

\section{Chronological Conversations}

\section{Prologue: Context for Conversations to Follow}

In this section we share our experiences teaching in Fall 2020 through a series of excerpts lifted from our monthly reflections conversations. We take a chronological approach to reflecting on the semester and begin with an introduction, followed by the reflection, and close with our interpretation of the conversation. Each month revealed a different theme that related to what we were individually and collectively experiencing throughout the semester.

\section{August}

Our reflections began in the last week of August, 2020. At this point Tia was well into the third week of the semester whereas Amy had just begun her first week.

\begin{tabular}{ll}
\hline Amy & Tia \\
\hline $\begin{array}{l}\text { My students are anxious. They } \\
\text { email me more than I feel }\end{array}$ & It feels like everything is changing this semester. \\
would be usual. & $\begin{array}{l}\text { I am doing a lot more checking on students this semester. } \\
\text { For instance, if a student isn't logged into the course, I ask } \\
\text { others to do a text check in on them. }\end{array}$ \\
\hline
\end{tabular}

Early in the semester we found ourselves very focused on our students and their wellbeing. As our courses began, we focused on course materials and methods for presenting it.

\begin{tabular}{l}
\hline Amy Tia \\
\hline Ifind that I am distilling what's important and \\
being more thoughtful about what is delivered \\
by zoom and what is strictly independently \\
online. I feel like I'm leaving out a lot of what \\
would have happened in the classroom each
\end{tabular}


day and then I wonder if that is a deficit or if those things were always "fluff" and not needed. These thoughts keep me up at night.

I guess I just feel a constant struggle of what to sacrifice and whether something is being sacrificed that is essential to learning about teaching literacy.
The expectations for my own teaching are decreasing with every class in regard to "getting through the material" and are more focused on well-being and the human side of teaching and addressing student questions that come up related to the content they are digesting asynchronously.

Technology failures have dictated what I compromise in the course. I am also looking at online writing lessons that students can examine and critique.

I find that I am sacrificing live action demos

and replacing them with videos.

The theme for August was struggle and transition. August was a beginning and a struggle for both of us. We were worried for our students and their needs both academic and personal. We were worried about our new context for teaching and reaching out to students. We both worked to temper the expectations for ourselves as teachers with delivering the content we felt was needed to best prepare our students for becoming teachers. We found ourselves in the in between much like Ando (2020) described as the process of maintaining balance in the midst of the pandemic while trying to envision a new normal post pandemic. In August we faced a painful transition. Universities like ours pre-pandemic were still relying on face-to-face instruction and often found that online only instruction could be insufficient for both students and teachers. There is often anxiety, a lack of confidence with technology and other barriers to overcome transitioning to an online environment (Ando, 2020). We were forced into this transition without notice, and this definitely raised our anxiety and provided discomfort as we attempted to find some type of equilibrium.

Kidd and Murray (2020) were studying their work with student teachers in England at this same time as our study. They described that their students were forced to rethink everything about their education and their changing home environments. They also reported, as we were describing, that as instructors they were having to think deeper than ever about knowledge and content their students needed in the new context (Kidd \& Murray, 2020). They were concerned with the level of effort put forth by both teachers and students and how this could be sustained. We were beginning to have these same questions and concerns.

\section{September}

In September, we found ourselves worried about our students and distilled content to what was most important. It was also in September that we began to look at our individual teaching identities. 


Amy
This month has been a blur. I have noticed that
I am skimming the fat and getting down to
what's truly important for students to know.

I think I define teaching as very active and in the moment between teacher and student. I don't feel like I'm teaching. I feel like I'm developing and designing for independent learning.

\section{Tia}

I am becoming less rigid in my expectations and due dates and asking more questions about how students are doing.

I am not sure it (hyflex teaching) is making me a better teacher of content, but I am a better teacher in regard to knowing my students as humans. My perception of teaching as a profession is changing rapidly and I am unsure if I can sustain this pace until the end of the semester., let alone guide my students through the end of the semester.

I am distilling content down and taking out activities that might have been supported in a classroom setting. I am attempting to do this based upon research and what I feel will be most meaningful or necessary.

My own identity as a teacher is changing in that I am far more aware of what is important in regard to the course outcomes and being laser focused on those as it relates to my instructional time with students and what material I present to students.

My students are definitely becoming divided into three groups: I have the overachievers that are constantly in touch with me. I have those that are doing well and getting by. I have students that have failed. They failed to respond to email communications. Then, they failed to turn in their large core assessment. They have spent a total of an hour logged into the course shell. They failed themselves. I still owned it.

I have students who are thriving in this environment and going above and beyond in their assignments and some who are not responsive to emails. Are students performing their best right now, probably not, but then again, neither am I. 
September's theme was identity. Our teaching identities shifted and changed with the ever-changing context of our circumstances. We found a need to adapt our definitions of teaching, but we struggled with naming the adaptations and feeling comfortable with the changes. Many teachers find their identity through interactions with students in a social world. Their identity is shaped by classroom events and the quality of human interactions in the classroom space (Hong, Francis, 2020). We constructed our teaching identities in this manner and were now faced with the absence of so many pieces of that context. Most teacher educators use constructivist teaching methods and work to promote student to student interaction. They interpret their jobs to center on supporting the development of new teachers in a classroom setting (Richter, Brunner, and Richter, 2020). We had defined our teaching in this manner and our identities were forced to shift radically and quickly. For Amy, her identity as a teacher was directly tied to a physical classroom where she was/is able to see and feel the energy of her students. For her, seeing the hyflex classroom as a physical classroom was a challenge between what she had experienced and was able to create with her students throughout her career to a new, online space where the classroom walls were not as defined. For Tia, the hyflex space allowed her to release the rigidity of a physical classroom and allowed for flexibility with her students, but there were still doubts if students were able to retain the content.

\section{October}

October was the month of grace. We noticed our need to extend grace to our students as they struggled to meet expectations set in a "normal" semester.

Amy
I am finding myself more solidly
identifying teaching as an action verb and
I'm defining that action as in a classroom
with face-to-face interaction. I don't feel
like a teacher in the online context. I feel
like a monitor.

My definition of stewarding my students has expanded greatly. From seeing them as only preservice teachers into the full human beings that they are and teachers they are becoming.

\footnotetext{
When a student requests a Zoom meeting to discuss one on one then I feel like a teacher. The interaction and then back and forth all figure into the act of teaching and to my identity. Without it I feel less fulfilled, less useful, less effective.
}

Tia

My perception of teaching is changing in that it feels like I am more of a counselor, mentor, and guide this semester more than a writing methods content teacher. 
being understanding. In the online context I find I'm bombarding them with articles and videos and PowerPoint to be sure all is covered.
I have adapted Voice and Comment for student assignments and that has been a game changer for me. I am able to click a button and leave audio comments on student assignments. Far more effective than when I would leave a written comment embedded in the assignment. Student feedback has been positive as well. So I feel good about that.

I'm extending some grace with a missed meeting or a missed deadline if students communicate with me. This decision has been guided by the stress and anxiety I sense as students think about student teaching in a Covid 19 world.

Students are exhausted and I am sure it is not just because of the course work; the world is heavy right now.

Students are stressed. Students are
fatigued.

I would say that it is really hard for them (students) to be present and in the moment while they are in class. They have mentioned concerns about student teaching, getting a job, and being confused about other course finals.

They (students) are doing well on assignments and assessments, and it appears they are doing the viewing and reading necessary. Students have a great deal of anxiety with the uncertainty of the virus and how it may change their student teaching and future teaching experiences.

I can say that I have more late assignments this semester, but then again, I am not deducting points for late work right now. However, the depth of the work in the assignments is what I would expect.

October's theme was definitely grace. Both of us found that we lowered our previous expectations and demands to meet the needs of students' emotional well-being. We extended deadlines, accepted late work, and modified assignments. We did all of these things while still trying to deliver necessary content in meaningful ways for all students. We were beginning to feel the weight of all of it and exhaustion was nearing. For Tia, the exhaustion came with constantly having to make decisions based on her students' experiences, both in and out of the classroom, meaning that for her, a lot of her energy was spent with student (either one on one or whole group) interaction. Those decisions ranged from changing an assignment due date to referring students to campus resources to fears about student teaching and the unknown. For 
Amy, the exhaustion also came from the constant decision making in new territory and the energy expended attempting to meet all needs, including her own teaching needs.

In this phase of our study, we saw some of the findings highlighted in What Teacher Educators Should Have Learned in 2020. In the introduction, Ferdig and Pytash refer to COVID as a magnifying glass, showing us where we need to grow (2021). They remind us that there must be a social and emotional connection behind the screen just as there was for students in a physical setting, perhaps even more so as students feel disconnected socially. COVID made us find different ways to reach our students and shone a light on ways that we were not reaching them.

As we noticed student fatigue and extended grace to students, we also began to notice our own fatigue and the need to extend grace to ourselves. We experienced a need for resources and support to deal with our questions of what it means to be a teacher of teachers in this new context of hyflex learning and teaching during and post pandemic (Richter, Brunner, Richter, 2021).

\section{November}

November brought things to an untidy close. There was no epiphany. There was no beautiful and hopeful conclusion. It was just an end with time for reflection. The messiness of balancing care for our students, delivering appropriate and quality content, and changing our identity as a teacher was prevalent in our conversations.

\begin{tabular}{l} 
Amy \\
\hline I'm barely hanging on and just \\
trying to wrap up without losing \\
my mind. I've adapted \\
expectations in terms of \\
responsibility. I've given up a lot of \\
control.
\end{tabular}

Teaching is not as active for me. It has become passive - something I do in advance and then hope it works. It is no longer interactive no give and take with students in the moment. Tia

I am questioning assignments, learning outcomes,
standards, all of it. I am far more focused on the
purpose and mission than ever.

I have received more emails from students about the course than ever before.

I have compromised so much.

There are so many activities I do in 
person that I did not feel I could

provide in the online environment.

It's not the same at all.

Overall, I think the more adaptive and responsive that I have been to students - when a week was really heavy, reducing assignments; continually getting feedback from them; and making sure that my graduation was caught up and I was giving productive feedback - the "easier" it was to teach.

Students are DONE. My students are just checking boxes at this point. They are frustrated and anxious about student teaching and just want to put this semester behind them.

Nothing felt forced or rushed this semester. And there was a lot, a lot, a lot, of grace given and received this semester as well.

November's theme was continued uncertainty. November did not bring answers but simply more questions to ponder as we move into what may be a new normal in our teaching to come. We continued to wrestle with balancing grace and high expectations. We continued to wrestle with defining ourselves as teachers in this new context. While we found we were willing to extend grace to our students in the context of the pandemic we also found that we were not as willing to extend that grace to ourselves. It may be time to reflect on that notion more deeply as we continue teaching in a post pandemic world.

We set out on this study hoping to study the new social world created by a pandemic from the perspective of two individuals interacting within it (Denzin, 2016). We sought interpretation and understanding. Realizing that changes arise cumulatively we sought to examine problems faced and how they might be addressed by engaging in a qualitative study (Torrance, 2017). What we learned is that there is still much to be learned but a structured reflection framework was a support as we worked through the experiences and looked toward the future.

This study was guided by a framework for reflection consisting of five questions decided upon by the participants at the onset. This structure guided our reflection in valuable ways. It kept the data collection and subsequent conversations focused upon what we wanted to explore and study and helped us to avoid what we term "teacher lounge talk". In the midst of uncertainty surrounding our work during the pandemic it would have been easy for us to meet and exchange complaints or stories or to simply commiserate over our struggles. Often this is what occurs in the teachers' lounge of a school. A visit to the lounge during recess or lunch is an unstructured time to share experiences. For us, we knew that we had to move past that surface level sharing to a more focused and productive means for reflection in hopes of learning and growing from our struggles. By utilizing a structured approach to our data collection and discussions we were able to hone in on the things we wanted to examine closely and to cut out the extraneous noise sometimes found in the lounge setting. 


\section{Moving Forward}

\section{Amy}

Engaging in this study brought unexpected results. I set out to join Tia in a qualitative study of how the pandemic was changing our teaching world and changing how we worked with students. I did learn a great deal about those aspects of our semester in the midst of constant change. Perhaps the most important thing I learned, however, was how important our colleagues are when we face uncertain times. There is power in sharing our stories, facing our challenges together, trusting enough to share our failures and having someone to be vulnerable with in the face of chaos. Utilizing a consistent reflective framework with five questions over time helped to organize our shared thoughts and focus our discussions.

Moving forward I believe my teaching will be changed. Though still not my preferred method, I have learned to teach online, and I'd like to believe it is becoming more effective. Face to face teacher education courses will resume but there will likely be online courses offered as an option for distance students. I will no longer be able to define my teaching as solely face to face. I will likely be teaching in an online environment in some aspect. I will be reshaping how I define teaching as I engage in a more hybrid approach. I will continue to distill the knowledge and content I want to convey in engaging ways utilizing technology while also planning for a social context of a classroom. I will continue to struggle with what I now know to be the needs of students that may have been in the shadows prior to COVID. I will be more understanding of student environments and struggles. I will also extend more grace to myself while acknowledging that change is constant.

Moving forward my research will be changed. The shared experience of this study has been a source of emotional and professional support I didn't even know I was craving. I will be engaging in more collaborative inquiry and not working alone. I'll be reaching out to others to share ideas and struggles, and I'll be modeling this for the preservice and in-service teachers I work with in my day-to-day activities in my institution. I plan to utilize a similar reflection framework as used in this study. Focusing the data collection and discussion provides clarity and consistency.

Perhaps Covid will pass, and things will return to some semblance of what we remember as normal. But we will all remain changed and there will always be a new challenge or barrier to overcome as we grow as educators.

\section{Tia}

I distinctly remember talking to Amy about this project and saying that I wanted to have fun writing. In fact, our professional relationship was built on writing, and it felt natural to have fun while working on this project together. This project was fun in that I enjoyed the work and co-wrote something that is unique from any of my other research in that it is deeply personal and brought out my humanity as an educator unlike anything I have done before. By engaging in consistent reflection throughout the fall semester, with a trusted colleague, I was able to uncover aspects of my teaching that have been absent since I was in the elementary classroom ten years prior.

Moving forward, I am redefining how I view myself as an academic. In the fall semester, I became laser focused on purpose and mission and found myself listening to students and advocating for their needs as I changed what needed to be changed within to meet their collective needs while still upholding the integrity of the course and the program. I have continued to advocate for my students and find myself becoming more vocal in how I am advocating for myself and others at my institution in how our needs are being met as the world transitions to post-pandemic life. 
Before, there has always been a sort of distance between myself and my research, in that I have had the role as researcher first. However, in this study, I was an active participant and that was a vulnerable position to be in and even now, I find myself wanting to retract some of what I had said. Now, had I removed myself from the study and not been open and honest in my reflection, I would be the more rigid and closed-off instructor that I was pre-COVID.

As educators, we sometimes find ourselves in a teaching rut and this process of constant reflection, with a trusted colleague, really helped to revive myself as a teacher and advocate for others. And moving forward, that is exactly what I want to model for my preservice and Inservice teachers, that when things are hard, and we know that teaching is hard, that is when you rally and reach out to trusted colleagues to go through the experience together.

\section{Conclusion}

For us, the framework for reflection anchored us in a semester where it would have been easy to lose our way as educators. The structured reflection questions, dedicated time each month, and the space to be honest with ourselves was invaluable to remind ourselves of why we do what we do, and continue to stay in the field of education, even when it is really hard.

We encourage other educators to pause and reflect on their own practice as the profession continues to change and confronts challenges outside of the classroom. We encourage other educators to utilize a structured reflection process when seeking to understand, grow, and learn. Using this approach can move the discussion from the teachers' lounge to an eventual plan of action for creating positive change.

\section{Disclosure Statement}

No financial interest or benefit has arisen from the direct applications of this research.

\section{References}

Ando, S (2021) University teaching and learning in a time of social distancing: A sociocultural perspective, Journal of Human Behavior in the Social Environment, 31: 1-4, 435-448, DOI: 10.1080/10911359.2020.1814928

Creswell, J. (2013). Qualitative inquiry and research design: Choosing among five approaches. Sage Publications.

Denzin NK. Critical Qualitative Inquiry. Qualitative Inquiry. 2017;23(1):8-16. doi:10.1177/1077800416681864

Ferdig, R.E. \& Pytash, K.E. (Eds). (2021). What Teacher Educators Should Have Learned from 2020. Association for the Advancement of Computing in Education (AACE). Retrieved March 17, 2021 from https://www.learntechlib.org/p/219088/

Hong, J \& Francis, D.C. (2020) Unpacking complex phenomena through qualitative inquiry: The case of teacher identity research, Educational Psychologist, 55:4, 208-219, DOI: $10.1080 / 00461520.2020 .1783265$

Kidd, W \& Murray, J (2020) The Covid-19 pandemic and its effects on teacher education in England: how teacher educators moved practicum learning online, European Journal of Teacher Education, 43:4, 542-558, DOI: 10.1080/02619768.2020.1820480

Norris, J. \& Sawyer, R. (2012). Toward a dialogic method. In J. Norris, R. Sawyer, \& D. Lund (Eds.), Duoethnography: Dialogic methods for social, health, and educational research (pp. 9-40). Left Coast Press.

Richter, E.,Brunner, M., Richter, D. Teacher educators' task perception and its relationship to professional identity and teaching practice,Teaching and Teacher Education,Volume 101,2021,103303,ISSN 0742-051X,https://doi.org/10.1016/j.tate.2021.103303. 
Seidel, J., \& Hill, L. (2015). Thinking together: A duoethnographic inquiry into the implementation of a field experience curriculum. In Education, 21(2). NP.

Tlale, L. D. N., \& Romm, N. R. A. (2019). Duoethnographic storying around involvements in, and extension of the meaning of, engaged qualitative research. FQS Forum: Qualitative Research, 20 (1), Article 7.

Torrance H. Experimenting with Qualitative Inquiry. Qualitative Inquiry. 2017;23(1):69-76. doi:10.1177/1077800416649201

\section{Notes on Contributors}

Tia Frahm, PhD, is a literacy assistant professor at Northern Arizona University. Her research interest is in professional learning that include the tenants of teacher programs, writing, and coaching contexts. She teaches undergraduate writing methods and graduate literacy courses. Tia is the coordinator of the K-8 Reading Specialist Program, serves as field council member for the Literacy Research Association, and partners with the AZ K-12 Center to work with Arizona educators.

Amy Spiker, EdD, is the Executive Director of the Literacy Research Center and Clinic at the University of Wyoming. She teaches courses in elementary education and works with teachers at all levels in literacy assessment and instruction. She has taught both undergraduate and graduate level courses in Literacy and Educational Foundations K-12. She has also served as a residency supervisor for student teachers and as a Director of Field Placements. She holds a National Board Certification in Literacy; Early and Middle Childhood.

Manuscript received August 2, 2021

Final revision received September 15, 2021

Accepted September 15, 2021 